\title{
STUDI PENGETAHUAN PASIEN TENTANG PENGGUNAAN AMLODIPIN TABLET DI KLINIK NUR ICHSAN MAKASSAR
}

\author{
*)Zulfiah, *)Kurnia Dayani \\ *)Akademi Farmasi Sandi Karsa Makassar \\ *)Program Studi D-III Farmasi Sandi Karsa Makassar
}

\begin{abstract}
ABSTRAK
Hipertensi merupakan gangguan kesehatan yang sering dijumpai dan termasuk kesehatan masyarakat yang perlu segera ditanggulangi. Tanpa penanggulangan yang baik, penyakit ini akan mengganggu kehidupan penderita sehari-hari dan cenderung dapat menimbulkan komplikasi. Penelitian ini bertujuan sebagai studi untuk mengetahui pengetahuan pasien tentang penggunaan amlodipin tablet di Klinik Nur Ichsan Makassar. Jenis penelitian ini adalah deskriptif dengan menggunakan instrument kuesioner yang dibagikan kepada 38 responden yang datang berobat di Klinik Nur Ichsan Makassar dan diberi amlodipin tablet sebagai antihipertensi yang telah diresepkan oleh dokter. Kategori pengetahuan tinggi jika skor jawaban $76 \%$ - 100\% dan pengetahuan rendah jika skor jawaban 50\% - 75\%. Dari hasil penelitian disimpulkan bahwa pengetahuan pasien tentang penggunaan amlodipin tablet sebesar $69,73 \%$ dimana jumlah persen menunjukkan bahwa pasien yang datang berobat memiliki pengetahuan yang rendah tentang penggunaan amlodipin tablet.
\end{abstract}

Kata Kunci : Pengetahuan, Penggunaan Tablet Amlodipin.

\section{PENDAHULUAN}

\section{A. Latar Belakang}

Dengan kondisi alam dan masyarakat saat ini yang sangat kompleks, semakin banyak bermunculan berbagai masalah. Masalah kesehatan yang cukup dominan baik di negara maju maupun di negara berkembang yaitu semakin banyaknya penderita hipertensi atau tekanan darah tinggi (Dalimartha, 2008).

Hipertensi merupakan gangguan kesehatan yang sering dijumpai dan termasuk kesehatan masyarakat yang perlu segera ditanggulangi. Tanpa penanggulangan yang baik, penyakit ini akan mengganggu kehidupan penderita sehari-hari dan cenderung dapat menimbulkan komplikasi. Hambatan dalam pengobatan ini disebabkan penderita yang lalai, tidak mendengarkan nasihat dokter atau apoteker, kurang pengetahuan dan pemahaman dalam minum obat serta kurangnya pengetahuan mengenai obat yang benar sehingga perlu kerjasama yang erat antara tenaga kesehatan dan pasien (Notoadmodjo, 2007). Pengetahuan merupakan hasil mengingat suatu hal, termasuk mengingat kembali kejadian yang pernah dialami baik secara sengaja maupun tidak sengaja dan ini terjadi setelah orang melakukan kontak atau pengamatan terhadap suatu objek tertentu. Faktorfaktor yang mempengaruhi tingkat pengetahuan seseorang yaitu umur, pendidikan, informasi, pengalaman dan pendidikan (Mubarak, 2007).

Terapi untuk pasien hipertensi terdiri dari terapi farmakologis dan terapi non farmakologis. Terapi farmakologis dapat menggunakan obatobatan untuk menurunkan tekanan darah. Terapi non farmakologis dapat dilakukan dengan memodifikasi gaya hidup seperti menurunkan berat badan, berhenti merokok, menghindari alkohol, mengurangi stres, memperbanyak olahraga dan istirahat yang cukup (Notoadmodjo, 2007).

Amlodipin merupakan salah satu obat hipertensi (penurun tekanan darah tinggi) yang tergolong dalam antagonis kalsium. Antagonis kalsium dimaksudkan untuk menghambat masuknya ion $\mathrm{Ca}$ ke dalam sel. Ion $\mathrm{Ca}$ harus dihambat karena apabila kadar ion Ca dalam sel meningkat, dapat merangsang kontraksi otot polos sehingga meningkatkan beban jantung (Davey, 2005).

Berdasarkan data awal peneliti yang diperoleh dari petugas kesehatan di Klinik Nur Ichsan Makassar bahwa obat hipertensi yang paling banyak diresepkan oleh dokter untuk penderita hipertensi adalah amlodipin tablet dan beberapa pasien masih memiliki pengetahuan yang kurang mengenai penggunaan obat hipertensi yaitu amlodipin tablet. Maka dari itu, peneliti tertarik untuk melakukan penelitian mengenai "Studi Pengetahuan Pasien Tentang Penggunaan Amlodipin Tablet di Klinik Nur Ichsan Makassar".

\section{B. Rumusan Masalah}

Adapun rumusan masalah dalam penelitian ini, yaitu bagaimana pengetahuan pasien tentang penggunaan amlodipin tablet di Klinik Nur Ichsan Makassar?

\section{Tujuan Penelitian}

Adapun tujuan dari penelitian ini yaitu untuk mengetahui tingkat pengetahuan pasien tentang penggunaan amlodipin tablet di Klinik Nur Ichsan Makassar. 


\section{Manfaat penelitian}

Melalui penelitian ini akan diperoleh informasi mengenai pengetahuan pasien tentang penggunaan amlodipin tablet di Klinik Nur Ichsan Makassar dan dapat menjadi masukkan dalam bentuk informasi yang bermanfaat.

\section{METODE PENELITIAN}

\section{A. Jenis Penelitian}

Jenis penelitian ini adalah penelitian deskriptif dengan menggunakan instrumen kuesioner.

\section{B. Waktu Dan Tempat Penelitian}

Penelitian ini dilaksanakan pada bulan Maret 2019 di Klinik Nur Ichsan Makassar.

\section{Populasi Dan Sampel}

\section{Populasi}

Populasi dalam penelitian ini yaitu sebanyak 60 pasien yang diberikan amlodipin tablet sebagai antihipertensi yang telah diresepkan oleh dokter di Klinik Nur Ichsan Makassar pada bulan Maret Tahun 2019.

2. Sampel

Sampel dalam penelitian ini yaitu sebanyak 38 pasien yang diberikan amlodipin tablet sebagai antihipertensi yang telah diresepkan oleh dokter di Klinik Nur Ichsan pada bulan Maret Tahun 2019. Besar sampel ditentukan menggunakan rumus slovin.

Inklusi:

1.Terdiagnosis hipertensi dalam dokumen rekam medik

2.Mendapatkan/menggunakan amlodipin tablet

3.Berusia 25-65 tahun

4.Bersedia mengisi kuesioner penelitian

Eksklusi:

1.Ibu hamil

2.Wali dari pasien

\section{Teknik Pengambilan Sampel}

Teknik Pengambilan sampel dalam penelitian ini menggunakan convenience sampling. Convenience sampling adalah teknik pengambilan sampel berdasarkan kebetulan, anggota populasi yang ditemui peneliti dan bersedia menjadi responden yang dijadikan sampel.

\section{E. Teknik Penarikan Sampel}

Teknik penarikan sampel dalam penelitian ini menggunakan rumus slovin.

$$
\begin{aligned}
\mathrm{n} & =\frac{\mathrm{N}}{1+\mathbb{N} \cdot e^{2}} \\
\mathrm{n} & =\text { Jumlah sampel penelitian } \\
\mathrm{N} & =\text { Jumlah populsi } \\
\mathrm{e}^{2} & =\text { persesi (ditetapkan } 10 \% \text { dengan tingkat } \\
\mathrm{n} & \text { kepercayaan } 90 \%) \\
\mathrm{n} & \frac{60}{1+60 \cdot 0,1^{2}}
\end{aligned}
$$

$$
\begin{aligned}
& \mathrm{n}=\frac{60}{1+60.0,01} \\
& \mathrm{n}=\frac{60}{1,6} \\
& \mathrm{n}=38 \text { sampel }
\end{aligned}
$$

\section{F. Kriteria Objektif} yaitu:

Dengan melihat kategori tinggi dan rendah

Tinggi : Jika skor jawaban $76 \%-100 \%$

Rendah : Jika skor jawaban 50\% - 75\%.

\section{G. Pengumpulan Data}

1. Sumber data berupa data primer yang dikumpulkan dengan membagikan kuesioner kepada responden.

2. Setiap pernyataan dalam kuesioner disediakan dalam 2 pilihan jawaban yaitu benar dan salah.

\section{H. Pengelolahan Data}

Data yang terkumpul selanjutnya diolah untuk menentukan persentase jawaban responden dengan menggunakan rumus:

Persentase skor $=$ Jumiah shor Hasil Pengumpulan Data

Shor terting $x$ i fumlah Item $x$ jumiah Responden $\times 100 \%$

Data kuesioner tersebut selanjutnya dibuat dalam bentuk tabel lalu ditentukan tingkat pengetahuan dan diberi nilai sebagai berikut: 1. Untuk jawaban benar, diberi skor $=2$

2. Untuk jawaban salah, diberi skor $=1$

\section{Analisis dan Penyajian Data}

Data yang diperoleh selanjutnya dianalisis untuk mengetahui sejauh mana pengetahuan pasien tentang penggunaan amlodipin tablet di Klinik Nur Ichsan Makassar dan disajikan dalam bentuk tabel.

Data yang diperoleh diolah menggunakan Skala Guttman, selanjutnya faktor yang mempengaruhi ditentukan berdasarkan pilihan jawaban responden.

\section{HASIL DAN PEMBAHASAN}

\section{A. Hasil Penelitian}

Hasil penelitian ini diperoleh berdasarkan kuisioner yang telah dibagikan kepada responden sebanyak 38 pasien sesuai dengan kriteria yang telah ditetapkan.

Berikut ini karateristik dan skor hasil jawaban dari 38 pasien sebagai sampel atau responden dalam penelitian ini.

Tabel I. Karakteristik Responden Berdasarkan Jenis Kelamin

\begin{tabular}{lcc}
\hline Jenis Kelamin & Jumlah ( Responden) & Persen (\%) \\
\hline Laki-laki & 15 & $39,5 \%$ \\
\hline Perempuan & 23 & $60,5 \%$ \\
\hline Jumlah & 38 & $100 \%$ \\
\hline \multicolumn{2}{c}{ Sumber : Data Primer 2019.}
\end{tabular}


Berdasarkan tabel diatas menunjukkan bahwa, responden yang berjenis kelamin lakilaki sebanyak 15 orang $(39,5 \%)$ dan yang berjenis kelamin perempuan yaitu sebanyak 23 orang $(60,5 \%)$.

Tabel II. Karakteristik Responden Berdasarkan Umur

\begin{tabular}{lcc}
\hline Umur & Jumlah (Responden) & Persen (\%) \\
\hline $25-34$ tahun & 6 & $15,8 \%$ \\
\hline $35-44$ tahun & 11 & $28,9 \%$ \\
\hline $45-54$ tahun & 13 & $34,2 \%$ \\
\hline $55-65$ tahun & 8 & $21 \%$ \\
\hline Jumlah & 38 & $100 \%$ \\
\hline
\end{tabular}

Sumber : Data Primer 209.

Berdasarkan tabel diatas menunjukkan bahwa, responden yang berumur $25-34$ tahun berjumlah 6 orang $(15,8 \%)$, responden yang berumur $35-44$ tahun berjumlah 11 orang $(28,9 \%)$, responden yang berumur 45-54 tahun berjumlah 13 orang dan responden yang berumur 55-65 tahun berjumlah 8 orang $(21 \%)$.

Tabel III. Karakteristik Responden Berdasarkan Jenis Pekerjaan

\begin{tabular}{lcc}
\hline $\begin{array}{c}\text { Pekerjaan } \\
(\%)\end{array}$ & Jumlah (Responden) & Persen \\
\hline Mahasiswa/I & - & - \\
\hline PNS & 4 & $10,5 \%$ \\
\hline Wiraswasta & 10 & $26,3 \%$ \\
\hline IRT & 19 & $50 \%$ \\
\hline Lain-lain & 5 & $13,2 \%$ \\
\hline Jumlah & 38 & $100 \%$ \\
\hline Sumbr: Data Priner
\end{tabular}

Sumber : Data Primer 2019.

Berdasarkan tabel diatas menunjukkan bahwa, tidak ada responden yang berprofesi sebagai mahasiswa/i, responden yang berprofesi sebagai PNS sebanyak 4 orang $(10,5 \%)$, sebagai wiraswasta sebanyak 6 orang $(15,8 \%)$, sebagai IRT sebanyak 19 orang $(50 \%)$ dan sebanyak 9 orang $(23,7 \%)$ yang berprofesi lain-lain. Adapun profesi lain-lain yaitu security sebanyak 2 orang, tukang becak 1 orang, pembantu rumah tangga 1 orang dan pegawai PLN sebanyak 1 orang.

Tabel IV. Rekapitulasi Jawaban dari 38 Responden

\begin{tabular}{ccc}
\hline $\begin{array}{c}\text { Tingkat } \\
\text { Pengetahuan }\end{array}$ & $\begin{array}{c}\text { Jawaban Skor } \\
\text { Responden }\end{array}$ & Persentase \\
\hline Rendah & 530 & $69,73 \%$ \\
\hline Sumber: Data Primer 2019, sudah diolah
\end{tabular}

Berdasarkan tabel diatas menunjukkan bahwa persentase skor jawaban $69,73 \%$ termasuk kategori pengetahuan rendah, ini berarti tingkat pengetahuan pasien di Klinik Nur Ichsan Makassar tentang penggunaan amlodipin tablet sangatlah kurang.

\section{B. Pembahasan}

Hipertensi merupakan gangguan kesehatan yang sering dijumpai dan termasuk kesehatan masyarakat yang perlu segera ditanggulangi. Tanpa penanggulangan yang baik, penyakit ini akan mengganggu kehidupan penderita sehari-hari dan cenderung dapat menimbulkan komplikasi. Pengobatan hipertensi yang baik yaitu dengan selalu mengontrol tekanan darah secara teratur dengan memeriksakan diri ke dokter dan meminum obat hipertensi secara tepat dan teratur sesuai nasihat dari tenaga kesehatan.

Penelitian ini bertujuan sebagai studi untuk mengetahui pengetahuan pasien tentang penggunaan amlodipin tablet di Klinik Nur Ichsan Makassar pada bulan Maret 2019. Dengan memberikan kuesioner kepada pasien yang datang berobat berobat dan diberi amlodipin tablet sebagai antihipertensi yang telah diresepkan oleh dokter yang berisikan pernyataan-pernyataan dan bersedia menjawab kuesioner.

Adapun hasil penelitian yang telah dilakukan menunjukkan bahwa persentase data pengetahuan pasien tentang penggunaan amlodipin tablet di Klinik Nur Ichsan Makassar sebesar 69,73\% (Tabel IV) termasuk kategori rendah, dimana jumlah persen menunjukkan bahwa pasien yang datang berobat memiliki pengetahuan rendah mengenai penggunaan amlodipin tablet. Hal ini dipengaruhi oleh beberapa faktor, diantaranya pasien memperoleh informasi yang kurang dari tenaga kesehatan atau farmasis mengenai penggunaan amlodipin tablet yang diresepkan kepada mereka, kurangnya keinginan pasien untuk bertanya pada tenaga kesehatan atau farmasis mengenai amlodipin tablet dan kurangnya keinginan pasien untuk mengetahui amlodipin tablet sebagai antihipertensi.

Adapun pernyataan-pernyataan pada kuesioner yang membuat pengetahuan pasien masuk dalam kategori rendah yaitu sebagian besar responden menjawab salah pada pernyataan amlodipin tablet memiliki dosis $5 \mathrm{mg}$ dan $10 \mathrm{mg}$, menurut ISO Volume 50 tahun 2016 bahwa amlodipin tablet hanya memiliki dosis $5 \mathrm{mg}$ dan $10 \mathrm{mg}$. Semua responden menjawab salah pada pernyataan amlodipin tablet sebaiknya diminum sebelum makan atau dalam kondisi perut kosong, menurut ISO Volume 50 tahun 2016, amlodipin sebaiknya diminum pada saat kondisi perut kosong karena adanya makanan dapat mengganggu proses yang dialami obat sebelum obat diserap ke dalam darah dan memberikan khasiat. Sebagian besar responden menjawab salah pada pernyataan kombinasi amlodipin tablet dapat dan simvastatin dapat merusak jaringan otot, menurut buku interaksi obat jika amlodipin dan simvastatin diminum bersamaan akan dapat merusak jaringan otot, maka dari itu simvastatin diminum pada pagi hari dan amlodipin diminum pada malam hari. Kemudian sebagian 
besar responden menjawab salah pada pernyataan amlodipin tablet tidak dapat dikonsumsi dengan buah anggur, menurut buku interaksi obat tidak direkomendasikan mengonsumsi amlodipin bersamaan dengan buah anggur karena dapat meningkatkan kadar amlodipin dalam darah.

\section{PENUTUP}

\section{A. Kesimpulan}

Berdasarkan hasil penelitian dan pembahasan yang telah diuraikan, maka dapat disimpulkan bahwa pengetahuan pasien yang datang berobat di klinik Nur Ichsan Makassar tentang penggunaan amlodipin tablet termasuk dalam kategori rendah, hal ini dapat dilihat dari persentase skor jawaban responden sebesar $69,73 \%$ (Tabel IV) dimana jumlah persen menunjukkan bahwa pasien yang datang berobat di klinik Nur Ichsan Makassar memiliki pengetahuan yang rendah tentang penggunaan amlodipin tablet.

\section{B. Saran}

Berdasarkan kesimpulan diatas, disarankan agar tenaga kesehatan atau farmasis dapat memberikan pelayanan informasi obat yang lebih jelas kepada pasien mengenai penggunaan amlodipin tablet, terutama waktu minum, efek samping, dosis, kontraindikasi dan interaksi antara amlodipin tablet dengan makanan dan obat-obatan lain.

\section{DAFTAR PUSTAKA}

Anief, M. 2010. Penggolongan Obat Berdasarkan Khasiat dan Penggunaan. Gadjah Mada University Press; Yogyakarta

Baharuddin. 2013. Perbandingan Efektivitas Dan Efek Samping Obat Antihipertensi Terhadap Penurunan Tekanan Darah Pasien Hipertensi. Fakultas Kedokteran Universitas Hasanuddin; Makassar.

Cahyono, S. 2008. Gaya Hidup dan Penyakit Modern. Kanisius; Jakarta

Dalimartha, S. 2008. Care Your Self Hipertention. Penebar Plus; Jakarta.

Gunawan, S. 2007. Farmakologi Dan Terapi Edisi 5. Departemen Farmakologi dan Terapeutik. Fakultas Kedokteran Universitas Indonesia; Jakarta

Mubarak. 2007. Promosi Kesehatan Sebuah Pengamatan Proses Belajar Mengajar Dalam Pendidikan. Graha Ilmu; Yogyakarta
Mutaqqin, A. 2010. Pengkajian Keperawatan Aplikasi Pada Praktik Klinik. Salemba medika; Jakarta

Neal, M. J. 2006. Farmakologi Medis Edisi 5. Erlangga; Jakarta

Notoadmodjo, S. 2003. Pendidikan Dan Perilaku Kesehatan. PT. Rineka Cipta; Jakarta

Notoadmodjo, S. 2007. Promosi Kesehatan dan Ilmu Perilaku. PT. Rineka kk Cipta; Jakarta

Notoadmodjo, S. 2010. Metodologi Penelitian Kesehatan. PT. Rineka Cipta: Jakarta

Nugroho, A. E. 2012. Obat-Obat Penting dalam Pembelajaran Ilmu Farmasi Dan Dunia Kesehatan. Pustaka Pelajar; Yogyakarta

Suryana, A. 2014. Kadar Zinc, Cuprum Dan Selenium Pada Penderita Hipertensi Primer Dan Normotensi. Universitas Airlangga; Surabaya

Siregar, C. J. 2004. Farmasi Rumah Sakit Teori Dan Penerapan. Penerbit Buku Kedokteran ECG; Jakarta

Sustrani, L. 2004. Hipertensi. Gramedia Pustaka Utama; Jakarta

Tjay H, Rahardja K. 2008. Obat-obat Penting, Khasiat, Penggunaan dan Efek-efek Sampingnya Edisi VI. Dirjen POM, Departemen Kesehatan Republik ndonesia; Jakarta 